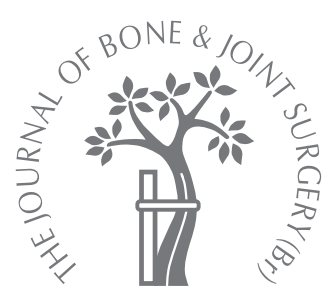

M. A. Khan

From The Bismillah Taqee Hospital, and the Medical Institute of Neurology and Rehabilitation, Karachi, Pakistan
ㅍ. A. Khan, MBBS, FCPS Fellow of College of Physicians and Surgeons (Pakistan) Consultant Orthopaedic Surgeon

Park Lane Hospital, 56 Old Clifton, Sharah-e-Iran, Karachi 75600 , Pakistan.

Correspondence should be sent to $\operatorname{Dr}$ M. A. Khan; e-mail: makbonedoc@cyber.net.pk

(c)2007 British Editorial Society of Bone and Joint Surgery doi:10.1302/0301-620X.89B8. $18475 \$ 2.00$

$J$ Bone Joint Surg $[\mathrm{Br}]$ 2007;89-B:1088-91. Received 31 July 2006; Accepted after revision 8 January 2007

\title{
Outcome of single-event multilevel surgery in untreated cerebral palsy in a developing
}

country

In developed countries, children with cerebral palsy are treated from the time of diagnosis. This is usually not the case in developing countries where such patients often present at an age when it is traditionally believed that if walking has not already commenced, it is unlikely to. This study reports the outcome of the surgical treatment of $\mathbf{8 5}$ spastic diplegic patients at a mean of 8.5 years (5 to 12). All presented as untreated non-walkers and had achieved sitting balance by the age of five to six years. They underwent single-event multilevel surgery followed by physiotherapy and orthotic support. For outcome assessment, a modified functional walking scale was used at a mean of 3.5 years (2 to 5 ) post-operatively.

At all levels, static joint contractures had resolved almost completely. All patients improved and became walkers, $18(21.2 \%)$ as exercise, $39(45.9 \%)$ as household and 28 $(33 \%)$ as community walkers.

This study shows that children with cerebral palsy who cannot walk and have not been treated can be helped by single-event multilevel surgery, provided that inclusion criteria are followed and a structural, supervised rehabilitation programme is in place.

Improved care of neonates has lead to an increased incidence of cerebral palsy $(\mathrm{CP}){ }^{1}$ In developed countries, the care of children with $\mathrm{CP}$ begins at diagnosis and involves rehabilitation, physiotherapy, ${ }^{2-4}$ medical treatment, ${ }^{1}$ injection of botulinum toxin ${ }^{5}$ and appropriate surgical operations, ${ }^{6}$ including single-event multilevel surgery, ${ }^{7}$ often preceded by instrumented gait analysis. ${ }^{8}$

In developing countries the position is very different. Diagnosis is often delayed, there are no special centres and, while physiotherapy is often recommended, its access is limited to the affluent minority. Bleck ${ }^{9}$ believed that patients with spastic diplegia can walk, but if they are not doing so by the age of seven years they may never walk. Paine ${ }^{10}$ felt that a child who was not walking by the age of eight years will never walk. This may be true when diagnosis is early, therapy is prompt and the brain damage is severe enough to preclude walking. The argument may not apply to a patient with CP presenting late when it is not known whether inability to walk is due to lack of treatment or severe initial brain injury. Furthermore, in children presenting late, non-surgical treatment may be expected to fail because of a greater amount of fixed contracture. There is no study, to the author's knowledge, which assesses the outcome of treatment by single event multilevel surgery in patients with CP who present late and cannot walk. This study evaluated the outcome of this treatment in such patients.

There is no established outcome measure for these children. Post-operative gait analysis is used widely, but it is not available in developing countries. It is nevertheless essential to have a valid outcome measure and the functional walking scale ${ }^{11}$ was selected. It was modified and incorporated into the grading of Hoffer et al $^{12}$ initially described for patients with myelomeningocele. Rang, Silver and Garza $^{13}$ have used it in patients with CP and this grading is commonly used in Pakistan. The ten levels of the functional walking scale were grouped into the four categories of Hoffer et al $^{12}$ (Table I). This was expected to document effectively the change after surgery if a patient showed improvement and moved up one category, rather than one level as recommended by Schwartz et al. ${ }^{14}$

\section{Patients and Methods}

Between January 2001 and December 2003, 98 children underwent surgery and 85 (53 boys, 32 girls) were followed up until December 2005 . Their mean age was 8.5 years $(5$ to 12). All the children had spastic-diplegia CP 
Table I. The modified functional walking scale, the ten levels of which have been placed in the categories of Hoffer et al. ${ }^{12}$ Improvement is considered to be significant if the child moves up one category

\begin{tabular}{|c|c|}
\hline Category & \\
\hline \multicolumn{2}{|l|}{ Non-walker } \\
\hline Level 1 & Cannot walk at all \\
\hline Level 2 & $\begin{array}{l}\text { Can do some stepping on his/her own with the help of another person. Does not take full weight nor walk as a rou- } \\
\text { tine }\end{array}$ \\
\hline \multicolumn{2}{|c|}{ Exercise walker } \\
\hline Level 3 & Walks for exercise in therapy and less than a household distance. Usually requires assistance \\
\hline Level 4 & $\begin{array}{l}\text { Walks for household distances, but makes slow progress. Does not use walking at home as prefered mobility. Prim- } \\
\text { arily walks in therapy }\end{array}$ \\
\hline \multicolumn{2}{|c|}{ Household walker } \\
\hline Level 5 & Walks 15 feet to 50 feet only inside home or school \\
\hline \multicolumn{2}{|c|}{ Community walker } \\
\hline Level 6 & Walks more than 50 feet outside but usually has a wheelchair or walker for longer distances or congested areas \\
\hline Level 7 & $\begin{array}{l}\text { Walks outside for community distances but only on level surfaces (cannot perform curbs, uneven terrain, or stairs } \\
\text { without assistance) }\end{array}$ \\
\hline Level 8 & $\begin{array}{l}\text { Walks outside the home for community distances, can perform curbs and uneven terrain and requires minimal } \\
\text { assistance or supervision for safety }\end{array}$ \\
\hline Level 9 & $\begin{array}{l}\text { Walks easily outside the home for community distances, but has difficulty or requires minimal help with running, } \\
\text { climbing and/or stairs }\end{array}$ \\
\hline Level 10 & Walks, runs and climbs without difficulty or assistance \\
\hline
\end{tabular}

and $34(40 \%)$ had additional mild upper limb involvement and $18(21 \%)$ had mild upper body involvement. They all had sitting ability, but $76(89 \%)$ could not sit fully erect. They all had good intelligence, but this was not measured. However, mental retardation is not reported as having a significant effect on walking ability. ${ }^{15,16}$ All were non-walking at level 1 and 2 of the functional walking scale. ${ }^{11}$ Those with any significant previous treatment, hip dislocation, and mental retardation enough to prevent comprehension of post-operative instructions were excluded as were patients with ataxia, dystonia or hemiballismus. No patient had residual primitive reflexes. ${ }^{9}$

The children were treated at two centres. One was an outpatient facility (Medical Institute of Neurology and Rehibilitation, Karachi, Pakistan) dedicated to patients with neuromuscular problems and staffed by neurologists, physiotherapists, occupational and speech therapists and an orthotist. Patients were brought by their parents or referred by general practitioners and other specialists. The other centre was a secondary-care hospital (Bismillah Taqee Hospital, Karachi, Pakistan) with referral mainly from paediatricians. All the operations were performed there by the author. Rehabilitation, orthotic fitting and post-operative assessments were carried out at the outpatient centre. ${ }^{11}$

Assessment of joint deformity included spasticity and estimation of the percentage of fixed versus dynamic contracture. The entire group, predominantly, had fixed contractures at each joint. This assessment was important since it revealed the extent of the intervention required, based on repeated examination and accurate documentation. Since all the children were unable to walk observational gait analysis could not be performed. The hip was assessed by the Thomas test ${ }^{13}$ and surgery undertaken if the flexion deformity was $15^{\circ}$ or more. A total of 75 children (88\%) needed surgery of the hip and had a mean fixed flexion of $30^{\circ}\left(15^{\circ}\right.$ to $\left.45^{\circ}\right)$. If there was absence of at least $45^{\circ}$ of abduction with the hip in extension, adductor tenotomy, without obturator neurectomy, was planned. This was undertaken in 63 children $(74 \%)$. The knee was assessed using the femoropopliteal angle. A total of 53 children $(62 \%)$ needed lengthening of the hamstrings, since their femoropopliteal angle was less than $90^{\circ} .{ }^{13,17}$

All the patients had tightness of gastrocnemius and soleus. If the equinus deformity was greater than $15^{\circ}$, Z-lengthening of the tendo Achillis was planned and undertaken. This was performed in 55 children $(65 \%)$.

Pre-operative care included anaesthetic and paediatric assessment. A total of 48 children $(56.5 \%)$ required treatment for problems such as anaemia, seizures and infections of the respiratory tract. All the children were admitted on the morning of surgery. After informed consent was obtained, they were given intravenous cefamazine according to their body-weight. The operations were performed under general anaesthesia, with additional caudal block given in 23 patients $(27 \%)$.

Soft-tissue surgery alone was required in 67 patients $(79 \%)$ and undertaken at three or more joints simultaneously. Of these, $45(53 \%)$ required extensive procedures to release the hip flexors and adductors, the medial and lateral hamstrings and the tendo Achillis. ${ }^{16,17}$ These procedures were performed through ten separate incisions, five in each limb. Five children $(5.9 \%)$ also required tendon transfers in the foot as well as soft-tissue release, while $18(21 \%)$ required additional bony procedures. These included bilateral rotation osteotomies of the femur, either proximal or 


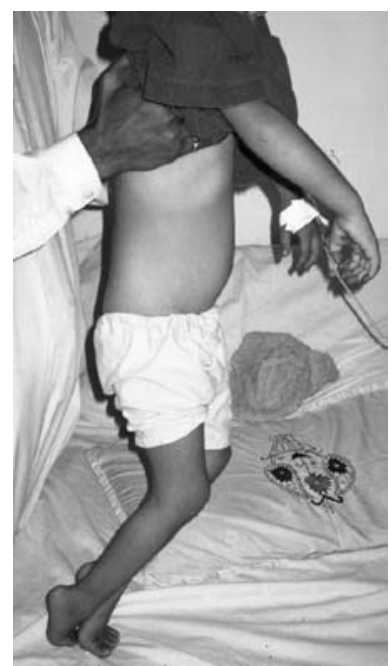

Fig. 1a

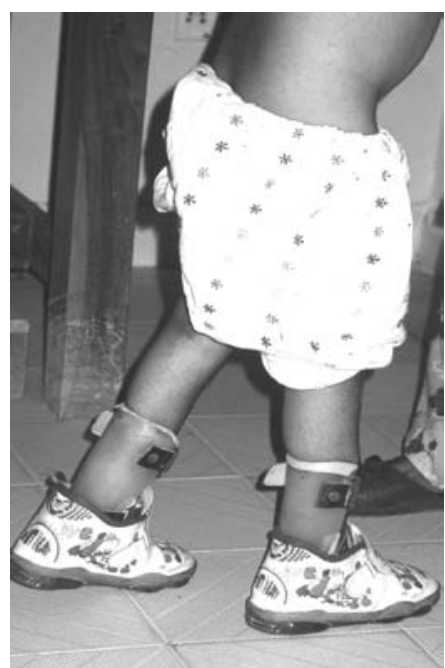

Fig. 1b
Photographs of a spastic diplegic child who presented at the age of six years, eight months showing a) that she was at level 1 on the functional walking scale and had never stood, and b) two months after soft-tissue lengthening at the hip and knee and Z-lengthening of tendo Achillis. Soon after surgery she had started to walk and achieved level 8 on the functional walking scale at 18 months.

distal $^{6}$ in 11 patients $(13 \%)$, and extension osteotomies of the distal femur in seven (8\%).18

All the operations were performed according to standard procedures apart from the release of hip flexion contracture. The usual practice of lengthening of the psoas has been reported to cause weakness of flexion. ${ }^{19}$ In our patients, the major cause of flexion deformity was tightness of tensor fascia lata, and of the 75 patients $(88 \%)$ undergoing correction of hip flexion contracture only ten $(12 \%)$ required lengthening of psoas. Most were adequately managed by release of the tensor fascia lata from the iliac crest, which was confirmed by an intraoperative Thomas test. The hip release was unilateral in five patients $(5.9 \%)$.

Long-leg plaster casts were applied with crossbars for those who had an adductor release. The stay in hospital was for only one day post-surgery for 74 patients $(87 \%)$. Six $(7 \%)$ stayed an additional day. Children with soft-tissue lengthening and tenotomies had casts, retained for six weeks in the first year of the study, and this was reduced to three weeks by the second year. After lengthening and repair of tendo Achillis the cast was removed after three weeks. Physiotherapy was started and splints made, but weight-bearing was delayed for six weeks. Patients who had osteotomies were in casts for approximately six weeks until healing was evident on radiographs. Patients who had tendon transfers at the foot retained the below-knee part of the cast for four to six weeks. All patients attended as outpatients, usually for between two and four days per week. Each session lasted for between one and three hours and consisted of physiotherapy, with speech and occupational
Table II. The categories attained by patients at the time of the final assessment. All patients had been at category 1 (level 1 and 2) on entry to the study

\begin{tabular}{lc}
\hline Category & Number of patients (\%) \\
\hline $\begin{array}{l}\text { Exercise walker (18 patients) } \\
\text { Level } 3\end{array}$ & $6(7)$ \\
Level 4 & $12(14)$ \\
& \\
Household walker (39 patients) & \\
$\quad$ Level 5 & $39(45.9)$ \\
& \\
Community walker (28 patients) \\
$\quad$ Level 6 \\
$\quad$ Level 7 \\
Level 8
\end{tabular}

therapy as required. The parents/guardians were given a home programme which was reinforced at each visit. These visits gradually became less frequent. All the children were taught exercises to improve their range of movement as outpatients and were provided with ankle-foot orthoses (Orthotic Department, Medical Institute of Neurology and Rehabilitation) for standing and walking. They had longleg gutter-type night splints. Several also needed therapy and splints for their upper limbs. A total of 51 children $(60 \%)$ initially needed therapy for one to two months merely to learn to stand in parallel bars from which they progressed to walkers, then crutches and sticks. The remaining patients were standing by one month after cast removal, in braces using the parallel bars. Five walked with support within two months (Fig. 1). A total of 76 patients $(89 \%)$ required long-leg splints to initiate standing before needing them at night only. Ankle-foot orthoses were not discontinued in any child.

\section{Results}

The final assessment was at a mean of 3.5 years (2 to 5 ) after operation.

At all levels, the static contractures in all the children were almost completely resolved except for a few degrees of static flexion at the knees in $15(17.6 \%)$. An estimated $10^{\circ}$ of dynamic flexion was retained at the knees in 23 children $(27 \%)$ when walking unaided, but this did not compromise function. Static hip flexion contractures resolved in all patients. None had residual adductor or ankle contracture.

The functional walking scale ${ }^{11}$ was undertaken by the author. All the children improved and moved out of the non-walking grade; $18(21.2 \%)$ progressed to be therapeutic walkers (level 3 and 4), 39 (45.9\%) to household walkers (level 5) and 28 to community walkers (level 6 to 10) (Table II). None improved beyond level 8 and only six $(7 \%)$ reached this level.

Complications. These were few. One child $(1.2 \%)$ had an intra-operative haemorrhage during lengthening of psoas, but did not require blood transfusion. One $(1.2 \%)$ had a superficial wound infection which settled with oral antibiotics and 
one $(1.2 \%)$ developed mild spasticity of rectus femoris after lengthening of the hamstrings but this did not require further surgery. Six $(7 \%)$ developed a minor abduction contracture after adductor tenotomies. These complications may be ascribed to operations which may have been unnecessary and suggest that pre-operative assessments in the absence of instrumented gait analysis can be prone to error.

As the children have grown, some of those operated on in 2001 and 2002 have developed problems, more commonly in those under six years of age at surgery. Four $(94.7 \%)$, all of whom had soft-tissue procedures initially, required femoral rotational osteotomies in 2006 . Two others $(2.3 \%)$ underwent further soft-tissue operations; lengthening of the hamstrings alone in one and additional lengthening of tendo Achillis in the other. These operations were performed before there was any deterioration in the functional walking scale and since they were undertaken some years after the study period, it is considered that they did not negate the results or count as complications.

\section{Discussion}

While the aim in this study was to initiate walking in an untreated group, it was not expected that all the children would become fully and independently ambulant. However, since all were walking and most had improved beyond therapeutic walking, the results are satisfactory. The fact that only $18(21 \%)$ became walkers at the exercise level is not disappointing overall.

While the principles of single-event multilevel surgery for CP are easily understood, they have been recommended for improving gait ${ }^{20}$ in patients who are walking and have not hitherto been evaluated as an initiator of this process. Various authors have attempted to estimate the walking potential of a patient with CP. Bleck ${ }^{9}$ used the presence or absence of primitive reflexes as a prognostic indicator. $\mathrm{Da} \mathrm{Paz}^{21}$ recommended the attainment of certain milestones and reported that achievement of head balance by nine months, independent sitting by two years and crawling at 30 months were good prognostic indicators for walking. Bleck ${ }^{9}$ and Paine ${ }^{10}$ also felt that independent sitting at two years was an important prognostic indicator. They also noted that a child who could not walk by the age of seven to eight years would not be able to do so. Molnar and Gordon, ${ }^{16}$ however, felt that independent sitting by the age of four years was more important for predicting future walking ability. If the opinions of authors other than Molnar and Gordon are accepted, the patients in this series would not merit treatment to help them to walk. A total of 13 $(15.3 \%)$ had head control at nine months and only 15 $(17.6 \%)$ were sitting independently at two years, but all had attained sitting ability by the age of five years. It is therefore felt that the recommendations of Molnar and Gordon ${ }^{16}$ are more applicable, and inability to sit by two years does not preclude walking potential. Also, whereas Nene, Evans and Patrick $^{22}$ felt that the ideal age for intervention was after seven years in children who did not improve. This is a different scenario when compared with the patients in this study.
I have shown that patients with CP and spastic diplegia who are untreated, present late, and cannot walk can be helped by single-event multilevel surgery provided that the inclusion criteria described are followed. Even children over seven or eight years of age can be helped, but it is important that they should have attained independent sitting by the age of four to five years. For a child with spastic diplegia, surgery alone is not enough. They will not walk automatically and a fully-staffed rehabilitation centre is essential for satisfactory results to be obtained.

The functional walking scale proved easy to implement and, when combined with the measurement of improvement of fixed joint deformity, allowed a good assessment of function. It is important that follow-up of these children is maintained beyond two years post-operatively, since changes in growth can lead to deterioration.

No benefits in any form have been received or will be received from a commercial party related directly or indirectly to the subject of this article.

\section{References}

1. Kerr Graham H, Selber P. Musculoskeletal aspects of cerebral palsy. J Bone Joint Surg [Br]2003;85-B:157-66.

2. Bobath B, Bobath K. Motor development in the different types of cerebral palsy. New York: William Heinman Publishers, 1978.

3. Rood MS. Neurophysiological reactions as a basis for physical therapy. Phys Ther Rev 1954;34:444-9.

4. Knott M, Voss DE. Propriceptive neuromuscular facilitation: patterns and techniques. New York: Hoeber-Harper, 1956

5. Preiss RA, Condie DN, Rowley DI, Graham HK. The effects of botulinum toxin (BTX-A) on spasticity of the lower limb and on gait in cerebral palsy. J Bone Joint Surg [Br]2003;85B:943-8.

6. Tachdjian MO. The neuromuscular system: cerebral palsy. Pediatric orthopedics. Second ed. Vol. 3. Philadelphia: W. B. Saunders, 1990:1605-770.

7. Pirpiris $\mathbf{M}$, Trivett $\mathbf{A}$, Baker $\mathbf{R}$, et al. Femoral derotation osteotomy in spastic diplegia: proximal or distal? J Bone Joint Surg [Br] 2003;85-B:265-72.

8. Deluca PA, Davis RB, Ounpuu S, Rose S, Sirkin R. Alterations in surgical decision making in patients with cerebral palsy based on three dimensional gait analysis. J Pediatr Orthop 1997;17:608-14

9. Bleck EE. Locomotor prognosis in cerebral palsy. Dev Med Child Neurol 1975;17:18-25.

10. Paine RS. Cerebral palsy: symptoms and signs of diagnostic and prognostic significance. In: Adams JP, ed. Current practice in orthopedic surgery. Vol. 3. St Louis: Mosby-Year Book Inc, 1966.

11. Novacheck TF, Stout JL, Tervo R. Reliability and validity of the Gillette Functional Assessment Questionnaire as an outcome measure in children with walking disabilities. $J$ Pediatr Orthop 2000;20:75-81.

12. Hoffer MM, Felwell E, Perry R, Perry J, Bonnett C. Functional ambulation in patients with myelomeningocele. J Bone Joint Surg [Am]1973;55-A:137-41.

13. Rang M, Silver R, Garza J. Cerebral palsy. In: Lovell WW, Winter RB, eds. Pediatric orthopedics. Second ed. Vol. 1. Philadelphia: J.B. Lippincott Company, 1986:345-96.

14. Schwartz MH, Viehweger E, Stout J, Novacheck TF, Gage JR. Comprehensive treatment of ambulatory children with cerebral palsy. J Pediatr Orthop 2004;24:45-53.

15. Bleck EE. Orthopedic management of cerebral palsy. Philadelphia: Saunders, 1979

16. Molnar GE, Gordon SU. Cerebral palsy: predictive value of selected clinical signs for early prognostication of motor function. Arch Phys Med 1976;57:153-8.

17. Morrissey RT. Distal hamstring lengthening and posterior capsulotomy. In: Atlas of pediatric orthopedic surgery. Second ed. Philadelphia: Lippincott-Raven Publishers, 1996:54558.

18. Sage FP. Cerebral palsy. In: Crenshaw AH, ed. Campbells operative orthopedics. Eighth ed Vol. 4. St Louis: Mosby-Year Book, 1992:2287-382.

19. Bleck EE, Holstein A. lliopsoas tenotomy for spastic hip flexion deformities. Procs American Academy Orthopaedic Surgeons, 1963

20. Saraph V, Zwick E-B, Zwick G, et al. Multilevel surgery in spastic diplegia: evaluation by physical examination and gait analyses in 25 children. J Pediatr Orthop 2002;22:150-7.

21. Da Paz C. Walking prognosis in cerebral palsy: quoted by Renshaw ST. In: Morrissey RT, Weinstein SL, eds. Cerebral Palsy. Lovell and Winters Pediatric Orthopaedics. 4th ed. Philadelphia: Lippincott-Raven Publishers.

22. Nene AV, Evans GA, Patrick JH. Simultaneous multiple operations for spastic diplegia: outcome and functional assessment of walking in children with cerebral palsy in 18 patients. J Bone Joint Surg [Br]1993;75-B:488-94. 